Pol. J. Food Nutr. Sci., 2019, Vol. 69, No. 2, pp. 191-201 DOI: $10.31883 /$ pjfns/108526 http://journal.pan.olsztyn.pl

Original research article

Section: Food Quality and Functionality

\title{
Predicting the Botanical Origin of Honeys with Chemometric Analysis According to Their Antioxidant and Physicochemical Properties
}

\author{
Anna Kaczmarek*, Malgorzata Muzolf-Panek, Jolanta Tomaszewska-Gras, Piotr Konieczny \\ Department of Food Quality and Safety Management, Faculty of Food Science and Nutrition, \\ Poznañ University of Life Sciences, Wojska Polskiego 31, 60-624 Poznañ, Poland
}

Key words: honey, botanical origin, physicochemical analyses

The aim of this study was to develop models based on Linear Discriminant Analysis (LDA), Classification and Regression Trees (C\&RT), and Artificial Neural Network (ANN) for the prediction of the botanical origin of honeys using their physicochemical parameters as well as their antioxidative and thermal properties. Also Principal Component Analysis (PCA) and Cluster Analysis (CA) were performed as initial steps of data mining. The datasets consisted of 72 honey samples (false acacia, rape, buckwheat, honeydew, linden, nectar-honeydew and multifloral) obtained from different regions of Poland and collected between April 2014 and November 2016. Ash content, pH, free acidity, colorimetric coordinates in the CIELAB space (L*, a*, $\left.b^{*}, h^{*}, C^{*}\right)$, total phenolics content, antioxidant activity, and glass transition temperatures $\left(\mathrm{T}_{\mathrm{g}}\right)$ of the honey samples were determined. The first four principal components accounted for about $85 \%$ of the total variance. PC1 was highly correlated with colour intensity, the hue angle (h*), and total phenolics content, whereas PC2 was dominated by chroma $\left(\mathrm{C}^{*}\right)$ value and glass transition temperatures $\left(\mathrm{T}_{\mathrm{g}}\right)$. The CA dendrogram displays two clusters: one with light coloured honey samples and second with dark coloured honey samples. On the basis of the LDA analysis, the colour parameters possessed the highest discrimination power according to the botanical origin of honey samples. The models based on ANN and C\&RT algorithms were characterized by $100 \%$ accuracy. Study results demonstrate that the chemometric approach enables high-accuracy classification of honeys according to their botanical origin.

\section{INTRODUCTION}

Honey is the only food product produced by honeybees (Apis mellifera). Pursuant to the definition of the Council Directive [Council Directive, 2001/110/EC], honey is a sweet substance made by honeybees from the nectar of flowers, plant saps or excretions of plant-sucking insects. During honey production, bees transform the collected materials by combining them with specific substances of their own and leave the honey in honeycombs to ripen and mature. Thus, the unique composition and properties of honey stem from its origin [Bertelli et al., 2010]. All the honey is composed mostly of carbohydrates and also contains minerals, amino acids, proteins, vitamins, enzymes (diastase and invertase), organic acids (gluconic acid, acetic acid), volatile compounds, and phenolic compounds [Gheldof et al., 2002; Bogdanov et al., 2008; De La Fuente et al., 2011]. As it was shown in previous studies, honey exhibits various biological properties, including the antioxidant activity which is ensued from the content of such bioactive compounds as: antioxidant enzymes (catalase, peroxidase), ascorbic acid, carotenoids and phenolic compounds, including both the flavonoids and phenolic acids as well as products of Maillard reaction [Al-Mamary

\footnotetext{
* Corresponding Author: Tel.: +48 6184873 63; Fax: +48 6184875 12;

E-mail: anna.kaczmarek@up.poznan.pl (A. Kaczmarek)
}

et al., 2002; Gheldof et al., 2002; Bertoncelj et al., 2007; Estevinho et al., 2008; Alvarez-Suarez et al., 2010; Brudzynski $\&$ Miotto, 2011a,b]. The phenolic content and composition of honey depend strongly on nectar type [Meda et al., 2005; Al et al., 2009; Habib et al., 2014], thus the phenolic profile could potentially be used to determine the botanical origin of the honey [Beretta et al., 2005; Anjos et al., 2015; Nayik et al., 2016; Nayik \& Nanda 2016]. The origin of honey also highly influences its sensory properties, like colour and flavour. The colour of honey is closely related to its composition such as the presence of pigments, mainly chlorophylls, carotenoids and some phenolic compounds [Lazaridou et al., 2004]. Moreover, honey colour is influenced by storage conditions like time and temperature [Baltrušaityté et al., 2007]. The antioxidant activities of honeys have frequently been associated with their colour. Generally, the following tendency could be observed: the more darker the colour of the honey is, the most potent antioxidant properties it exhibits [Brudzynski $\&$ Miotto, 2011b, a]. Some studies have focused on the colour parameters to enable determination of the botanical origin of honey [Beretta et al., 2005; Juszczak et al., 2009; Tuberoso et al., 2014; Anjos et al., 2015; Nayik \& Nanda, 2016; Siddiqui et al., 2017]. The physicochemical properties of honey, like $\mathrm{pH}$, conductivity, water and ash content, are also influenced by its composition and thereby by its botanical origin. 
Recently, instead of measurements of individual parameters, a global approach has been recommended in the determination of the botanical origin of honeys. Thus, thermal analysis can be applied alongside other parameters. Differential scanning calorimetry enables the analysis of the thermal behaviour of a honey sample under changing temperatures. Honey, as a supersaturated aqueous solution, can undergo a characteristic phenomenon, i.e. glass transition, which occurs as an effect of heat capacity variation. The glass transition temperature $\left(\mathrm{T}_{\mathrm{g}}\right)$ can be used for the prediction of honey rheological behaviour [Lazaridou et al., 2004], for the assessment of its authenticity [Cordella et al., 2002], or for the determination of possibility of its spray drying [Tonon et al., 2009]. Glass transition temperature depends mainly on the moisture and honey type. Generally, the $\mathrm{T}_{\mathrm{g}}$ increases with a decreasing water content and an increasing molecular weight of solutes [Tomaszewska-Gras et al., 2015]. The main sugars of honey: fructose and glucose, also affect the $\mathrm{T}_{\mathrm{g}}$ value. However, the final $\mathrm{T}_{\mathrm{g}}$ is governed by the sugar ratio which depends on the botanical source and environmental conditions [Ahmed et al., 2007]. Unifloral honeys exhibit differences in flavours, biological activity, colours and other properties and together with honeydew honey are the most highly-priced bee products. In recent years, as an effect of the increasing fertilization of plant cultivars, honey has become the product of limited supply. All these favour the practice of honey adulteration. To protect the high quality of honey and to ensure its authenticity, specific regulations has been set by the EU [Council Directive, 2001/110/EC]. Thus, the authentication of honey - which means it should agree with its botanical and/or geographical origin - has become an important issue nowadays.

In recent years, numerous studies have addressed determinations of the botanical origin of honeys. The most frequently used method for the determination of honey adulteration and authenticity is the pollen analysis (mellisopalnyology). Nevertheless, as this procedure requires highly specialised personnel and is very time-consuming, it loses its importance as a fast routine method for assessing honey quality [Benedetti et al., 2004].

The botanical origin of honey can be assessed by combining physicochemical parameters ( $\mathrm{pH}$ as content, total acidity etc.) with multidimensional data analysis. Such an approach has shown good approximation [Anjos et al., 2015; Nayik \& Nanda, 2016; Popek et al., 2017].

To the best knowledge of authors, studies on the classification of Polish honeys are scarce [Madejczyk \& Baralkiewicz, 2008; Chudzinska \& Baralkiewicz, 2010; Popek et al., 2017].

The aim of the present investigation was to describe and classify Polish honeys (from various regions of Poland) according to their botanical origin based on a combination of their antioxidant properties, results of their thermal analysis, and values of their physicochemical parameters. The novelty of this study is to use thermal analysis and antioxidant properties together with other physicochemical parameters for the determination of the botanical origin. The underlying interrelations between parameters were studied using chemometric methods including unsupervised and supervised pattern recognition techniques.

\section{MATERIAL AND METHODS}

\section{Honey samples}

The present study was carried out using eight different types of honey, namely: false acacia (Robinia pseudoacacia) $\mathrm{n}=12$, rape (Brassica spp.) n=6, buckwheat (Fagopyrum esculentum) $\mathrm{n}=12$, honeydew $\mathrm{n}=9$, heather (Calluna vulgaris) $\mathrm{n}=6$, linden (lime) $\mathrm{n}=12$, nectar-honeydew $\mathrm{n}=3$, and multifloral $n=12$. The honeys came from various regions of Poland, were collected between April 2014 and November 2016, and were obtained from local associations of beekeepers. Honey samples were stored in the dark at room temperature $20-25^{\circ} \mathrm{C}$. Before analysis, they were heated in a bath $\left(35^{\circ} \mathrm{C}\right)$ for $20 \mathrm{~min}$ and homogenised.

\section{Ash content}

Ash content was determined by incinerating honey samples in a muffle furnace (Thermo Scientific ${ }^{\mathrm{TM}}$ M110 Muffle Furnaces, Germany) at a temperature of $550^{\circ} \mathrm{C}$ [AOAC, 1995], and expressed in $\mathrm{g} / 100 \mathrm{~g}$.

\section{Free acidity and pH}

Free acidity was measured by a titrimetric method AOAC 962.19 [AOAC, 1996]. 0.1 M NaOH was added to a $10 \% \mathrm{w} / \mathrm{v}$ solution of honey. The solution of honey was prepared with $\mathrm{CO}_{2}$ free distilled water, up to $\mathrm{pH} 8.3$. The results were expressed as milliequivalents $/ \mathrm{kg}$ (meq/kg). The $\mathrm{pH}$ values were measured with a $\mathrm{pH}$-meter (Microcomputer $\mathrm{pH}$ Meter CP551 , Elmetron, Poland) in a $10 \% \mathrm{w} / \mathrm{v}$ solution of honey in distilled water, according to the AOAC Official Method 962.19 [AOAC, 1996].

\section{Colour determinant values}

Colour indices $\left(\mathrm{L}^{*}\right.$ and $\left.\mathrm{a}^{*}, \mathrm{~b}^{*}\right)$ were measured by the CIELab system using a Minolta Chroma-meter (Spectrophotometer CM-5, Konica Minolta, Japan) with illuminant D65. It expresses colour as three numerical values, $L^{*}$ for the lightness and $\mathrm{a}^{*}$ and $\mathrm{b}^{*}$ for the green-red and blue-yellow colour components. Also the hue angle $\left(\mathrm{h}^{*}\right)$ and chroma $\left(\mathrm{C}^{*}\right)$ were calculated as:

$$
\begin{aligned}
& h^{*}=\tan ^{-1}\left(\frac{b^{*}}{a^{*}}\right) \\
& C^{*}=\left[\left(a^{*}\right)^{2}+\left(b^{*}\right)^{2}\right]^{\frac{1}{2}}
\end{aligned}
$$

Samples were illuminated at $45^{\circ}$. Measurements were made on homogenised honey samples.

\section{Colour intensity}

Honey sample colour intensity was measured using the method of Beretta et al. [2005]. Honey samples were diluted to $50 \%(\mathrm{w} / \mathrm{v})$ with warm $\left(45^{\circ} \mathrm{C}\right)$ deionised water and the solution was then filtered through a $0.45 \mu \mathrm{m}$ pore size filter. The absorbance readings were taken at 450 and $720 \mathrm{~nm}$ using a spectrophotometer (Varian Cary 1E UV/Visible Spectrophotometer, USA) and the difference in absorbance $\left(\mathrm{A}_{450}\right.$ $\left.-\mathrm{A}_{720}\right)$ was expressed as mAU. 


\section{Total phenolics content}

Total phenolics content was determined according to the method of Singleton \& Rossi [1965] with some modifications [Muzolf-Panek et al., 2016]. For total phenolics content determination, honey (10 g) was dissolved in $10 \mathrm{~mL}$ of deionised water. The solution was mixed in the dark at room temperature for $30 \mathrm{~min}$, and filtered $(0.45 \mu \mathrm{m}$ pore size filter). Then, the filtrate was centrifuged at $4000 \mathrm{rpm}$ for $5 \mathrm{~min}$. The supernatant was removed and filtrated again. The sample was prepared each time on the day of the analysis.

An aliquot of $20 \mu \mathrm{L}$ of honey extract was mixed with $100 \mu \mathrm{L}$ of Folin-Ciocalteu reagent and left to stand in a dark place at room temperature for $3 \mathrm{~min}$. Then, $300 \mu \mathrm{L}$ of sodium carbonate $(20 \% \mathrm{~m} / \mathrm{v})$ and $1580 \mu \mathrm{L}$ of deionised water were added and mixed. After $2 \mathrm{~h}$ of incubation, the absorbance was read at $765 \mathrm{~nm}$ against a blank sample (prepared as previously described but deionised water was used instead of the extract). For each sample, three separate determinations were conducted. All results were presented as mg gallic acid equivalent (GAE) per $100 \mathrm{~g}$ of honey sample.

\section{DPPH radical scavenging activity}

The antioxidant activity of honeys was evaluated by the socalled DPPH method according to the procedure of Sánchez-Moreno et al. [1998] with some modifications [Muzolf-Panek et al., 2016]. In brief, an aliquot of $10 \mu \mathrm{L}$ of honey extract (prepared as described above) was mixed with $990 \mu \mathrm{L}$ of $0.1 \mathrm{mM}$ DPPH in methanol. After 30 min of incubation at room temperature without the access of light, the absorbance was read at $515 \mathrm{~nm}$ using a spectrophotometer (Varian Cary 1E UV/Visible Spectrophotometer, USA). For each sample, three separate determinations were conducted. After the addition of the honey sample to the solution of $\mathrm{DPPH}^{*}$ in methanol, a decrease of absorbance was observed in comparison to the control sample. The higher was the concentration of the honey sample, the greater decrease of absorbance was obtained, and from the difference between the absorbance of the control sample and samples with honey the percentage of the scavenged $\mathrm{DPPH}^{*}$ was calculated. Then, the slope of the linear plot of the scavenged $\mathrm{DPPH}^{*}$ by the honey extracts versus honey concentration was determined. The antioxidant activity (AA) of honey sample was expressed as mmol Trolox equivalent (TE) per $100 \mathrm{~g}$ of honey. Additionally, $\mathrm{IC}_{50}$ values defined as the concentration of the sample which ensures $50 \%$ reduction of $\mathrm{DPPH}^{*}$ concentration were calculated.

\section{Thermal analysis}

Differential scanning calorimeter DSC 7 (Perkin Elmer, Norwalk, USA) was used to determine the glass transition temperature $\left(\mathrm{T}_{\mathrm{g}}\right)$ of honey samples. The device equipped with an Intracooler II and running under Pyris software 10.0 was calibrated using the standards of indium $\left(\mathrm{T}_{\mathrm{m}}=156.60^{\circ} \mathrm{C}, \Delta \mathrm{H}=\right.$ $28.45 \mathrm{~J} / \mathrm{g}$, Perkin Elmer) and n-dodecane (99.8 purity, $\mathrm{Tm}=$ $-9.65^{\circ} \mathrm{C}$, Merck). The honey samples were weighed into aluminum pans (Perkin Elmer, $50 \mu \mathrm{L}$ total volume, No. B016-9321) and hermetically sealed. The analysis of $\mathrm{T}_{\mathrm{g}}$ involved the following three steps: (1) heating from $25^{\circ} \mathrm{C}$ to $100^{\circ} \mathrm{C}$, with a scanning rate of $10^{\circ} \mathrm{C} / \mathrm{min}$; (2) cooling from $100^{\circ} \mathrm{C}$ to $-65^{\circ} \mathrm{C}$; and (3) heating from $-65^{\circ} \mathrm{C}$ to $100^{\circ} \mathrm{C}$, with a scanning rate of $10^{\circ} \mathrm{C} / \mathrm{min}$.
The reference was an empty, hermetically sealed aluminum pan. All the samples were analysed by the DSC in at least three replications. The obtained glass transition temperatures $\left(\mathrm{T}_{\mathrm{g}}\right)$ were calculated from the second heating scans as a midpoint temperature according to Tomaszewska-Gras et al. [2015].

\section{Statistical analysis}

Each honey sample was analysed in triplicate and the results are expressed as mean \pm standard deviations (SD). All statistical tests were performed using Statistica 13.0 software (StatSoft, Tulsa, Oklahoma, USA). Prior to multivariate analysis, the entire data matrix was standardised (except C\&RT analysis). Person's linear correlation coefficients (r) between selected parameters were calculated. Principal Component Analysis (PCA) and Cluster Analysis (CA) were used as the first step of multivariate data analysis to visualize information and to find patterns in data sets. Furthermore, linear discriminant analysis (LDA), classification and regression trees (C\&RT), and artificial neural networks (ANN) were used to calculate classification rules for sample discrimination. The significance level was set at $5 \%$.

\section{RESULT AND DISCUSSION}

\section{Physicochemical characteristics}

The results of the physicochemical measurements of all the types of honey samples are shown in Table 1. All the measured parameters are in accordance with the Polish Standards for honey [Polish Standard PN-A-77626:1998]. The highest ash content was recorded for honeydew honey $(0.8 \mathrm{~g} / 100 \mathrm{~g})$, next for nectar-honeydew honey $(0.46 \mathrm{~g} / 100 \mathrm{~g})$. This is consistent with the study of Popek et al. [2017] where ash content was 0.6 and $0.5 \mathrm{~g} / 100 \mathrm{~g}$, respectively. The lowest value in ash content was noted for multifloral honey $(0.17 \mathrm{~g} / 100 \mathrm{~g})$. The colour parameters of the selected honey types showed a high variability. The $\mathrm{L}^{*}, \mathrm{a}^{*}$ and $\mathrm{b}^{*}$ values of honey samples varied from 26 to $50,-3$ to 7 and 5.8 to 23 , respectively (Table 1 ). The obtained values indicate that almost all of the honey samples were dark coloured. Only the acacia honey can be classified as light coloured with an $\mathrm{L}^{*}$ value equaling 51 [Gonzalez-Miret et al., 2005]. Acacia, rape and multifloral honey samples possessed a green component (negative value of index $a^{*}$ ) whereas all the others possessed the red component (positive value of index $\left.\mathrm{a}^{*}\right)$. All the analysed honey samples had a yellow constituent in their colour. The colour intensity of a $50 \%$ (w/v) honey solution varied from $263 \mathrm{mAu}$ for the pale acacia honey to $1506 \mathrm{mAu}$ for the dark honeydew honey. This parameter is directly related to the occurrence and concentration of compounds containing conjugated double bonds such as terpenes, carotenoids, and flavonoids that absorb light in the visible range (400-700 nm) [Młodzińska, 2009]. As reported in Table 1, the total phenolic content was low in the pale honeys of monofloral origin, like in rape (5.5 mg GAE/100 g) and acacia (10.3 mg GAE/100 g) honeys, whereas the highest TPC value was noted for dark buckwheat honey (>60 mg GAE/100 g). A similar polyphenol content was recorded in the heather, arbutus, and locust podshrub honey collected from various regions of Portugal [Alves et al., 2013]. The TPC level recorded in this study for Polish buckwheat honey was markedly lower than the results obtained 
TABLE 1. Results of physicochemical parameters, antioxidant activity $\left(\mathrm{IC}_{50}, \mathrm{AA}\right)$, total phenolic content (TPC), and glass transition temperature ( $\left.\mathrm{T}_{\mathrm{g}}\right)$ of individual types of honey.

\begin{tabular}{l|c|c|c|c|c|c|c|c}
\hline $\begin{array}{l}\text { Type of honey/ } \\
\text { Measurement }\end{array}$ & Acacia & Buckwheat & Linden & Nectar-honeydew & Rape & Honeydew & Multifloral & Heather \\
\hline L $^{*}$ & $51 \pm 5.6$ & $33 \pm 8.7$ & $40 \pm 3.6$ & $31 \pm 0.1$ & $43 \pm 0.5$ & $26 \pm 1$ & $42 \pm 1.9$ & $26 \pm 0.4$ \\
$\mathrm{a}^{*}$ & $-3.41 \pm 0.44$ & $2.25 \pm 3.84$ & $0.46 \pm 1.86$ & $7.9 \pm 0.1$ & $-3.03 \pm 0.36$ & $6.32 \pm 1.22$ & $-1.14 \pm 1.05$ & $0.54 \pm 0.16$ \\
$\mathrm{~b}^{*}$ & $18.6 \pm 4.59$ & $8.39 \pm 3.48$ & $21.53 \pm 10.61$ & $15.57 \pm 0.06$ & $16.32 \pm 0.25$ & $7.89 \pm 1.39$ & $23.7 \pm 8.99$ & $5.8 \pm 0.21$ \\
$\mathrm{~h}^{*}$ & $-0.19 \pm 0.05$ & $0.22 \pm 0.35$ & $-0.04 \pm 0.17$ & $0.47 \pm 0.01$ & $-0.18 \pm 0.02$ & $0.67 \pm 0.04$ & $0.05 \pm 0.04$ & $0.09 \pm 0.03$ \\
$\mathrm{C}^{*}$ & $18.9 \pm 4.49$ & $9.29 \pm 3.88$ & $21.66 \pm 10.49$ & $17.46 \pm 0.07$ & $16.6 \pm 0.29$ & $10.11 \pm 1.81$ & $22.74 \pm 9$ & $5.83 \pm 0.2$ \\
$\begin{array}{l}\text { Colour intensity } \\
(\mathrm{mAu})\end{array}$ & $263 \pm 9.3$ & $1424 \pm 449.8$ & $532.8 \pm 191.6$ & $852.7 \pm 17.2$ & $229.1 \pm 28.1$ & $1506.8 \pm 104.1$ & $491.4 \pm 81.4$ & $1199 \pm 24.5$ \\
$\mathrm{pH}$ & $4.19 \pm 0.06$ & $4.07 \pm 0.16$ & $4.23 \pm 0.05$ & $4.78 \pm 0.01$ & $4.22 \pm 0.02$ & $5.02 \pm 0.4$ & $4.21 \pm 0.27$ & $4.25 \pm 0.01$ \\
$\begin{array}{l}\text { Free acidity } \\
(\mathrm{meq} / \mathrm{kg})\end{array}$ & $12.8 \pm 0.82$ & $34.25 \pm 10.67$ & $31.09 \pm 11.26$ & $22 \pm 0.5$ & $10.5 \pm 1.05$ & $32.67 \pm 1.49$ & $34.04 \pm 25.33$ & $32.33 \pm 1.03$ \\
$\begin{array}{l}\text { Ash content } \\
(\mathrm{g} / 100 \mathrm{~g})\end{array}$ & $0.2 \pm 0.02$ & $0.22 \pm 0.12$ & $0.19 \pm 0.09$ & $0.46 \pm 0.1$ & $0.22 \pm 0.1$ & $0.8 \pm 0.04$ & $0.17 \pm 0.04$ & $0.41 \pm 0.02$ \\
$\begin{array}{l}\text { IC } \\
(\mathrm{mg} / \mathrm{mL})\end{array}$ & $69.4 \pm 9.2$ & $28.1 \pm 3.7$ & $74.3 \pm 5.1$ & $19.9 \pm 2.7$ & $184.8 \pm 28.1$ & $14.28 \pm 1.1$ & $91.4 \pm 17.1$ & $113.8 \pm 18.8$ \\
$\begin{array}{l}\mathrm{TPC} \\
(\mathrm{mg} \mathrm{GAE} / 100 \mathrm{~g})\end{array}$ & $10.3 \pm 3.51$ & $62.33 \pm 9.64$ & $20.48 \pm 5.16$ & $42.85 \pm 5.83$ & $7.53 \pm 2.21$ & $48.75 \pm 9.98$ & $19.03 \pm 4.6$ & $31.72 \pm 6.23$ \\
$\begin{array}{l}\mathrm{AA} \\
(\mathrm{mmol} \mathrm{TE} / 100 \mathrm{~g})\end{array}$ & $56.3 \pm 6.4$ & $95.56 \pm 5.42$ & $30.50 \pm 1.28$ & $101.24 \pm 3.75$ & $11.29 \pm 2.12$ & $142.27 \pm 9.86$ & $27.63 \pm 5.97$ & $35.97 \pm 8.04$ \\
$\begin{array}{l}\mathrm{T}_{\mathrm{g}} \\
\left({ }^{\circ} \mathrm{C}\right)\end{array}$ & $-40.6 \pm 1.16$ & $-42.21 \pm 1.90$ & $-41.18 \pm 3.93$ & $-35.19 \pm 0.48$ & $-43.78 \pm 5.69$ & $-41.55 \pm 3.56$ & $-40.76 \pm 2.41$ & $-47.11 \pm 0.95$ \\
\hline
\end{tabular}

by Mellen et al. [2015] (296.22 mg GAE/100 g) and Dżugan et al. [2018] (135 mg GAE/100 g). These authors reported also the highest TPC values for rape, linden, nectar-honeydew, and honeydew honeys accounting for 25.45, 40.91, 63.03, and $60.01 \mathrm{mg} \mathrm{GAE} / 100 \mathrm{~g}$, respectively [Dżugan et al., 2018]. The results of the present study showed (Table 1) that the unifloral honeys, rape and heather, had the lowest antioxidant activity. Their $\mathrm{IC}_{50}$ values were 184.8 and $113.8 \mathrm{mg} / \mathrm{mL}$, respectively. The highest radical scavenging activity was noted in honeydew and nectar-honeydew honey samples $(14.28$ and $19.9 \mathrm{mg} / \mathrm{mL}$, respectively). It is difficult to compare directly results of the antioxidant activity and TPC of honeys with literature data. In previous researches, authors used various modifications of the DPPH assay and different units to express the results. However, the results concerning the antioxidant activity of acacia honey were similar to that obtained by Krpan et al. [2009] who showed that the mean antioxidant activity of acacia honey expressed as $\mathrm{IC}_{50}$ value was equal to $111 \mathrm{mg} / \mathrm{mL}$. Also the antioxidant activity of acacia honey reported by Bertoncelji et al. [2007] was very similar. However, the TPC value obtained in this study for acacia honey (10.3 mg GAE/100 g) was 2.5 times higher compared to literature data [Krpan et al., 2009; Bertoncelji et al., 2007]. Nevertheless, the TPC value of multifloral honey presented in this study (19 mg GAE/100 g) was similar to the TPC values reported by Bertoncelji et al. [2007] (15.7 mg GAE/100 g). Other authors reported a higher content of polyphenols in multiflower honey. In the Mellen et al. [2015] study, TPC values determined for multiflower honeys from different areas of Poland ranged from 61.12 to 99 (mg GAE/100 g). Also Dżugan et al. [2018] obtained higher TPC values for multifloral honey(49 mg GAE/100 g). Such large differences may be due to a very different content of pollen derived from various plants in the final product.
Generally, the $\mathrm{pH}$ value of honey is between 3.5 and 5.5 due to the presence of inorganic ions, such as phosphate and chloride and organic acids especially gluconic acid [Bogdanov et al. 2004]. Active acidity (pH) measurements can also be included in the identification of the botanical origins of honey [Sanz et al., 2005]. The highest $\mathrm{pH}$ value was noted in the honeydew honey samples (5.02) while the lowest one in the buckwheat (4.07) honey samples. The lowest value of free acidity was noted for rape honey $(10.5 \mathrm{meq} / \mathrm{kg})$, whereas honey with the highest acidity turned out to be buckwheat honey (with the mean value of $34.25 \mathrm{meq} / \mathrm{kg}$ ). These valeus are in accordance with the results obtained by Pasini et al. [2013] for buckwheat honey $(19.2-50.3 \mathrm{meq} / \mathrm{kg}$ ). It is known that honeydew honeys show a higher average acidity and $\mathrm{pH}$ value than blossom honey [Bentabol Manzanares et al., 2011].

\section{Thermal analysis}

Glass transition, measured by the DSC technique, was manifested by a change in heat capacity which induces a steplike change in the baseline of the curve (heat flow $v$ s. temperature). This transition occurs when the material changes upon cooling from a rubbery-like state into a hard, glassy state or conversely from a glassy solid to a rubbery state upon heating. Table 1 shows the values of the glass transition temperatures $\left(\mathrm{T}_{\mathrm{g}}\right)$ which were determined from the heating DSC curve as the midpoint. The $T_{g}$ values of the pure honey samples varied between $-35.19^{\circ} \mathrm{C}$ and $-47.11^{\circ} \mathrm{C}$ and were in strong agreement with literature data [Cordella et al., 2002; Tomaszewska-Gras et al., 2015]. The lowest temperature was determined for heather honey, which is known as one of those with the highest water content. According to Council Directive 2001/110/EC, water content in heather honey is allowed up to $23 \%$, while 
TABLE 2. Linear correlation coefficients between all measured parameters.

\begin{tabular}{|c|c|c|c|c|c|c|c|c|c|c|c|c|c|}
\hline & $\mathrm{L}^{*}$ & $a^{*}$ & $b^{*}$ & $\mathrm{pH}$ & $\begin{array}{c}\text { Free } \\
\text { acidity }\end{array}$ & $\begin{array}{c}\text { Ash } \\
\text { content }\end{array}$ & $\mathrm{IC}_{50}$ & $\mathrm{TPC}$ & AA & $\mathrm{T}_{\mathrm{g}}$ & $\mathrm{h}$ & $\mathrm{C}$ & \begin{tabular}{|c|} 
Colour \\
intensity
\end{tabular} \\
\hline $\mathrm{L}^{*}$ & 1.00 & & & & & & & & & & & & \\
\hline$a^{*}$ & -0.74 & 1.00 & & & & & & & & & & & \\
\hline$b^{*}$ & 0.57 & -0.32 & 1.00 & & & & & & & & & & \\
\hline $\mathrm{pH}$ & -0.42 & 0.47 & -0.18 & 1.00 & & & & & & & & & \\
\hline Free acidity & -0.33 & 0.31 & -0.30 & -0.06 & 1.00 & & & & & & & & \\
\hline Ash content & -0.68 & 0.67 & -0.47 & 0.78 & 0.18 & 1.00 & & & & & & & \\
\hline $\mathrm{IC}_{50}$ & 0.19 & -0.50 & 0.20 & -0.25 & -0.35 & -0.34 & 1.00 & & & & & & \\
\hline TPC & -0.72 & 0.70 & -0.55 & 0.24 & 0.37 & 0.44 & -0.60 & 1.00 & & & & & \\
\hline $\mathrm{AA}$ & -0.46 & 0.63 & -0.47 & 0.56 & 0.19 & 0.68 & -0.76 & 0.71 & 1.00 & & & & \\
\hline $\mathrm{T}_{\mathrm{g}}$ & 0.18 & 0.14 & 0.11 & 0.16 & 0.03 & -0.03 & -0.26 & -0.07 & 0.09 & 1.00 & & & \\
\hline $\mathrm{H}^{*}$ & -0.75 & 0.96 & -0.34 & 0.55 & 0.24 & 0.76 & -0.48 & 0.72 & 0.70 & 0.08 & 1.00 & & \\
\hline $\mathrm{C}^{*}$ & 0.53 & -0.23 & 0.99 & -0.14 & -0.31 & -0.41 & 0.17 & -0.50 & -0.41 & 0.12 & -0.26 & 1.00 & \\
\hline $\begin{array}{l}\text { Colour intensity } \\
\text { ABS } 450\end{array}$ & -0.85 & 0.74 & -0.61 & 0.30 & 0.43 & 0.64 & -0.45 & 0.89 & 0.68 & -0.21 & 0.78 & -0.56 & 1.00 \\
\hline
\end{tabular}

In italic there are reported the correlation coefficient values statistically insignificant at $\mathrm{p}>0.05$.

in the remaining types of honey it should not exceed $20 \%$. It is well established that water acts as a plasticizer and this caused a decrease in the $\mathrm{T}_{\mathrm{g}}$ point. In turn, the highest value of $\mathrm{T}_{\mathrm{g}}\left(-35.19^{\circ} \mathrm{C}\right)$ was recorded for the nectar-honeydew honey which was one of the darker honeys $\left(\mathrm{L}^{*}=31\right)$ with a high ash content $(0.46 \%)$.

Correlation, principal component and cluster analyses

In the preliminary investigation of the different types of honey, a correlation analysis as well as a principal compo- nent analysis (PCA) were performed. The correlation matrix (Table 2) showed a significant correlation between almost all parameters. The highest value of Pearson's correlation coefficient $(r=0.89)$ was determined between TPC and colour intensity. The significant correlation between the TPC and parameter $\mathrm{L}^{*}$ (measure of lightness) was negative, which indicated decreases in the TPC values with increases in light colour. This is proved by multivariate analysis (Figure 1). Principal component analysis was performed to explore dataset and to find any relationship between the variables. Using
(A)

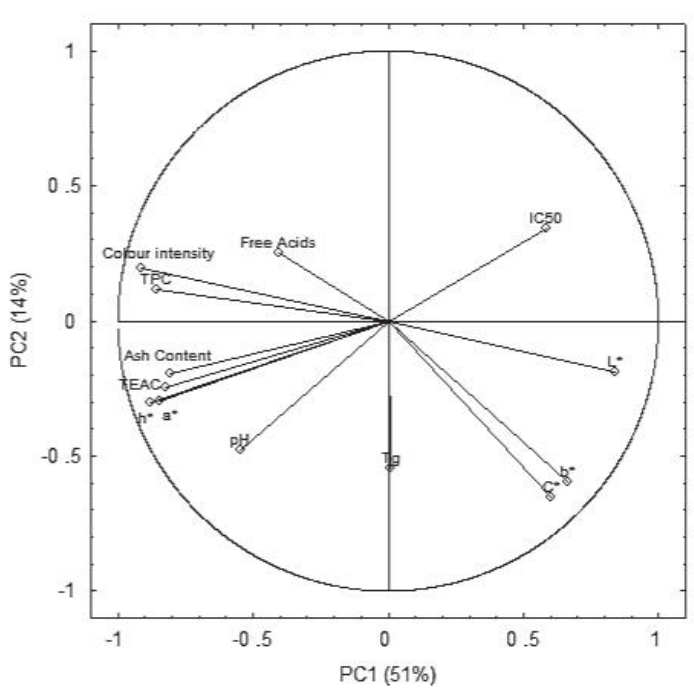

(B)

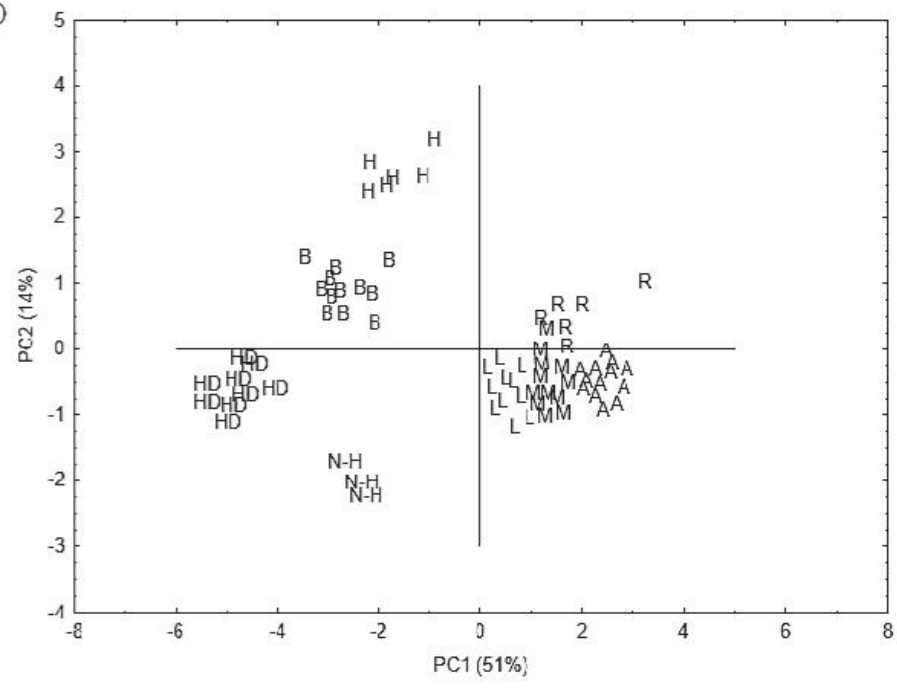

FIGURE 1. Principal component analysis results.

A) Projections of the variables on the facto plane. $\mathrm{L}^{*}, \mathrm{a}^{*}, \mathrm{~b}^{*}, \mathrm{~h}^{*}$ and $\mathrm{C}^{*}$ - colour indices, TPC - total phenolic content, IC50, AA - antioxidant activity, $\mathrm{Tg}$ - glass transition temperature. B) Projections of the scores on the factor plane. A - acacia honey, R - rape honey, L - linden honey, $\mathrm{M}$ - multifloral honey, $\mathrm{N}-\mathrm{H}$ - nectar-honeydew honey, B - buckwheat honey, $\mathrm{H}$ - honeydew honey, $\mathrm{H}$ - heather honey. 


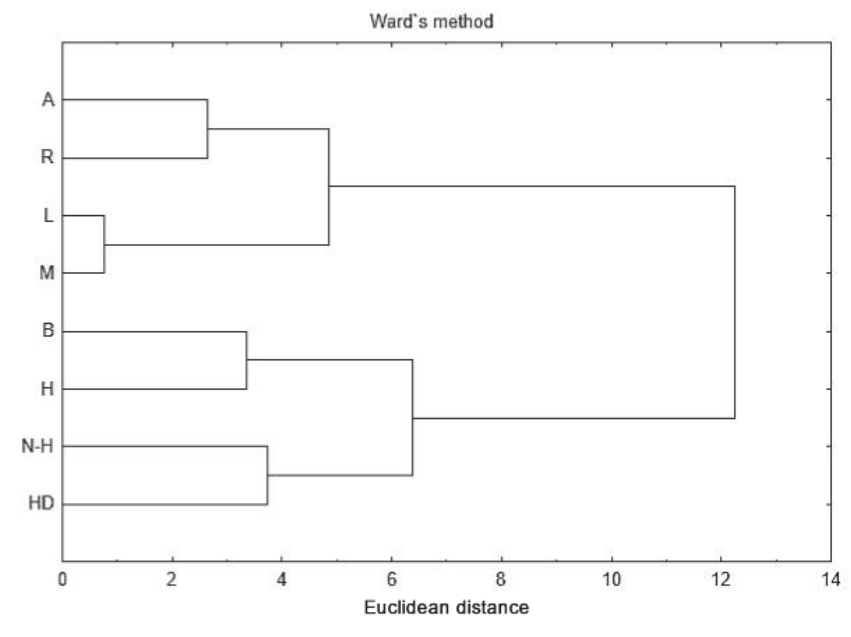

FIGURE 2. Dendogram of different honey types according to cluster analysis of similarity on the basis of antioxidant activity, thermal analysis, and physicochemical parameters.

(A - acacia honey, $\mathrm{R}$ - rape honey, $\mathrm{L}$ - linden honey, $\mathrm{M}$ - multifloral honey, $\mathrm{N}-\mathrm{H}$ - nectar-honeydew honey, $\mathrm{B}$ - buckwheat honey, $\mathrm{H}$ - honeydew honey, $\mathrm{H}$ - heather honey).

the graphical criterion, the first four principal components, with Eigen values greater than 1, were derived. The first four principal components accounted for about $85 \%$ of the total variance. The highest and the lowest loading values indicate the highest importance of parameters in determining sample distribution along the first PC. The first (PC1), second (PC2), third (PC3), and fourth (PC4) principal component explained $51 \%, 14 \%, 10 \%$, and $8 \%$ of the variance, respectively. The first component was predominated by colour intensity, $\mathrm{h}^{*}$ value, and total phenolic content, while the highest loading values of $\mathrm{C}^{*}, \mathrm{~b}^{*}$ and $\mathrm{T}_{\mathrm{g}}$ were noted in the second principal component. Figure $1 \mathrm{~B}$ showed the score plot of PCA. All light coloured honey samples on the right side of PC1 are linked to $\mathrm{L}^{*}$ colour parameter whereas dark coloured honey samples are located on the left side of PC1. Additionally, heather and buckwheat honeys are linked to free acidity and are located on the left side of PC2 while nectar-honeydew honey and honeydew honey are characterized by the higher ash content, the higher antioxidant activity, and the higher values of $\mathrm{a}^{*}$ colour parameter.

Another unsupervised pattern recognition method is cluster analysis (CA). The Ward method, known as the minimum variance method with Euclidean distance between centroids, was applied. In accordance with the CA dendrogram (Figure 2), eight well-separated clusters were observed. As shown in Figure 3, all darker honeys ( $\mathrm{N}-\mathrm{H}$ - nectar-honeydew honey, $\mathrm{B}$ - buckwheat honey, $\mathrm{H}$ - honeydew honey, $\mathrm{H}$ - heather honey) were heaped together in one cluster, while light coloured honeys ( $\mathrm{A}$ - acacia honey, $\mathrm{R}$ - rape honey, $\mathrm{L}$ - linden honey, $\mathrm{M}$ - multifloral honey) were heaped in the second separate cluster. The most similar, according to the measured parameters, were the linden and multifloral honeys. The smallest Euclidean distance was measured between these honeys. This similarity cloud disrupts the determination of linden and multifloral honeys. In addition, the distance determined between rape and acacia honeys was smaller than among other honeys.

\section{Linear Discriminant Analysis}

Linear Discrimination Analysis (LDA), is probably the most commonly used one among the supervised pattern recognition methods [Berrueta et al., 2007]. Standardised dis-

TABLE 3. Standardised canonical discriminant function coefficients.

\begin{tabular}{|c|c|c|c|c|c|c|}
\hline Variable & Root 1 & Root 2 & Root 3 & Root 4 & Root 5 & Root 6 \\
\hline $\mathrm{L}^{*}$ & 0.453 & 1.035 & -0.119 & -1.053 & 0.453 & 0.214 \\
\hline$a^{*}$ & 5.288 & -3.381 & -2.504 & -0.407 & 1.696 & -0.469 \\
\hline$b^{*}$ & 7.255 & 13.833 & -10.880 & 6.093 & 6.679 & 2.110 \\
\hline$h^{*}$ & -5.675 & 4.720 & 0.845 & 1.043 & -1.101 & 0.811 \\
\hline $\mathrm{C}^{*}$ & -6.286 & -15.385 & 11.407 & -6.325 & -7.234 & -1.752 \\
\hline Colour intensity & -0.008 & 1.242 & -0.196 & -0.305 & -0.999 & -0.770 \\
\hline $\mathrm{pH}$ & -0.282 & -0.937 & -0.515 & 0.078 & -0.631 & -0.133 \\
\hline Free acidity & -0.127 & -0.886 & 0.080 & 0.461 & -0.774 & 0.612 \\
\hline Ash content & -0.651 & -0.303 & -0.015 & -0.277 & 0.715 & 0.204 \\
\hline $\mathrm{IC}_{50}$ & 1.488 & -0.353 & -0.177 & -0.520 & 1.146 & 1.340 \\
\hline $\mathrm{TPC}$ & 2.505 & 0.125 & -0.309 & -0.787 & 0.991 & 1.049 \\
\hline AA & 0.131 & -0.470 & 0.074 & -0.508 & 0.352 & 0.353 \\
\hline $\mathrm{T}_{\mathrm{g}}$ & 0.631 & -0.427 & 0.350 & -0.781 & -0.299 & 0.109 \\
\hline Discrimination (\%) & 48.48 & 24.28 & 18.98 & 5.41 & 2.06 & 0.69 \\
\hline Cumulative (\%) & 48.48 & 72.76 & 91.74 & 97.15 & 99.21 & 99.89 \\
\hline
\end{tabular}

$\mathrm{L}^{*}, \mathrm{a}^{*}, \mathrm{~b}^{*}, \mathrm{~h}^{*}$ and $\mathrm{C}^{*}$ - colour indices, TPC - total phenolic content, $\mathrm{IC}_{50}, \mathrm{AA}-$ antioxidant activity, $\mathrm{T}_{\mathrm{g}}-$ glass transition temperature. 


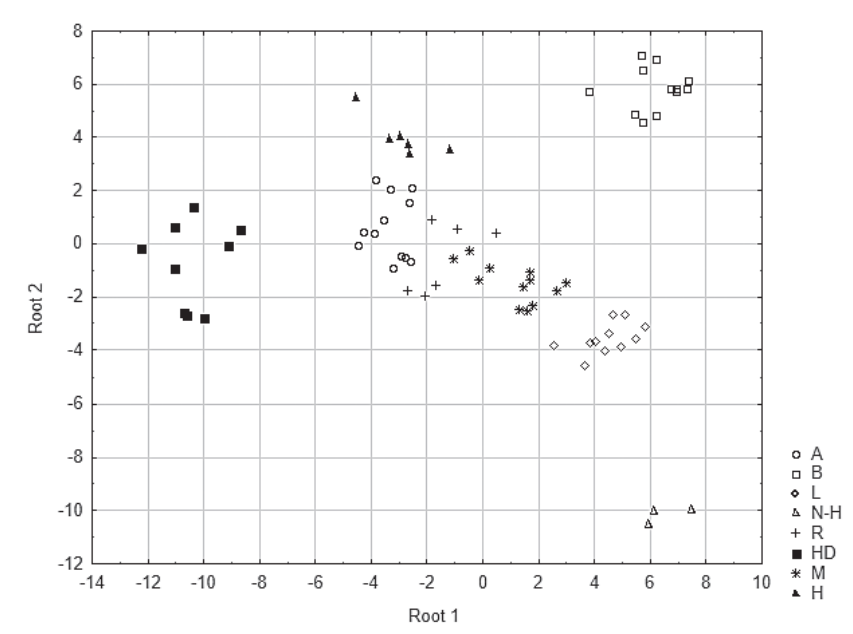

FIGURE 3. Linear discriminant analysis (LDA ) sample classification of honeys.

(A - acacia honey, $\mathrm{R}$ - rape honey, $\mathrm{L}$ - linden honey, $\mathrm{M}$ - multifloral honey, N-H - nectar-honeydew honey, B - buckwheat honey, $\mathrm{H}$ - honeydew honey, $\mathrm{H}$ - heather honey).

criminant coefficients were used to compare the relative importance of the independent variables (Table 3). The higher the absolute value of the standardised coefficient, the more important was the related independent variable. The first six discriminant functions were statistically significant and accounted for $99.9 \%$ of the total variance. The first discriminant function accounted for $48.5 \%$ of the total variance and the second for $24.2 \%$. Colour parameters $\left(b^{*}, a^{*}, h^{*}\right.$, and $\left.C^{*}\right)$ contributed the most to the canonical variable (Table 3 ). This means that the colour of honey had the highest discrimination power according to the botanical origin. Colour parameter $b^{*}$ contributed the most to the first canonical variable (standardized coefficient $=7.255$ ) accounting for most of the discrimination between honey classes. The second canonical variable was related to chroma $\left(\mathrm{C}^{*}\right)$ parameter (standardized coefficient $=$ -15.385) expounding the discrimination between the honeys according to their botanical origin. A scatter plot of canonical values (Figure 3 ) shows that the discrimination of honey types is noticeable. We can observe an excellent discrimination of dark coloured honeys (buckwheat, honeydew and nectar-honeydew honey) because the colour parameters possess the highest discriminating power. According to the classification matrix, almost all types of honey were classified correctly (98.61\%). Only one sample of multifloral honey was incorrectly classified as a rape honey type. Linear discriminant analysis was successfully used to predict the group membership of acacia, pine honeydew, and multifloral honey based on their mineral content and antioxidant properties [Nayik et al., 2016]. In that research, potassium contributed the most to the first canonical variable. Whereas, the second canonical variable was related to calcium. It was found that the mineral composition also helped in the determination of honey type. Similar results were obtained by Nayik \& Nanda [2016]. The cherry, apple, saffron, and wild bush honeys were discriminated using LDA. Mineral content, colour parameters, and electrical conductivity contributed the most to the first, second, and third canonical variable, respectively. The classification matrix proved the very strong classification ability of the constructed model.

\section{Classification and Regression Trees}

Classification and regression trees (C\&RT) are machine-learning methods for building prediction models from data. The tree develops by carefully searching for predictors in each branch for the best division in each node. The goal is that descendants are more homogeneous than their parents. When the split creates the positive change in prescient exactness, splits at every node will happen. V-fold cross-validation $(v=10)$ was used to avoid model over-fitting. Figure 4 shows the graph of the Decision Tree model for the classification of honey types.

The TPC values play the main role in the differentiation between light and dark coloured honeys, whereas the colour parameters possess the highest discrimination power in distinguishing between multifloral and linden honey samples. The ash content and temperature of glass transition $\left(\mathrm{T}_{\mathrm{g}}\right)$ were useful in the differentiation between different dark coloured types of honey. All honey samples were correctly classified. Therefore, the accuracy of the model is $100 \%$. In other research, the decision tree (C\&RT) was successfully used to determine honey type. Discrimination according to the botanical origin of honeys was based on their physicochemical properties. Clear rules that characterise the type of honey were obtained and in only one case was heather honey incorrectly classified as a multifloral one [Popek et al., 2017]. But in conclusion more honey samples (types of honey, regions and years of collection) should be examined to generalise the developed model.

\section{Artificial Neural Network}

The determination of the tested honey types was tackled with a pattern recognizer based on artificial neural network (ANN) providing nonlinearity in the multivariate classification performance. The available set of 72 points has been divided into: learning (75\%), training (15\%), and validating $(15 \%)$ sets. Multilayer feed-forward fully connected ANN has been trained with the Broyden-Fletcher-Goldfarb-Shanno learning algorithm (200 epoch). The search for an appropriate ANN model was performed using multilayer perceptron (MLP) and radial basis function (RBF) networks. The best seven networks of total 30 were chosen. The network structure developed for honey data included an input layer, one hidden layer and an output layer. The input layer made up of 13 neurons, 10-13 neurons in a hidden layer and eight neurons in the output layer (classification of honeys based on their botanical origin). The sums of squares and the crossentropy error function were used during the network training process. The best seven ANN-MLP networks are presented in Table 4. In all the obtained networks, the hyperbolic tangent function was used in the hidden layer, whereas the sine linear transfer and Softmax functions were also used in the output layer. The success of the model to classify objects can be evaluated as: training performance as a percentage of the samples in the learning set correctly classified during the networks learning step; test performance as a percentage of the samples 


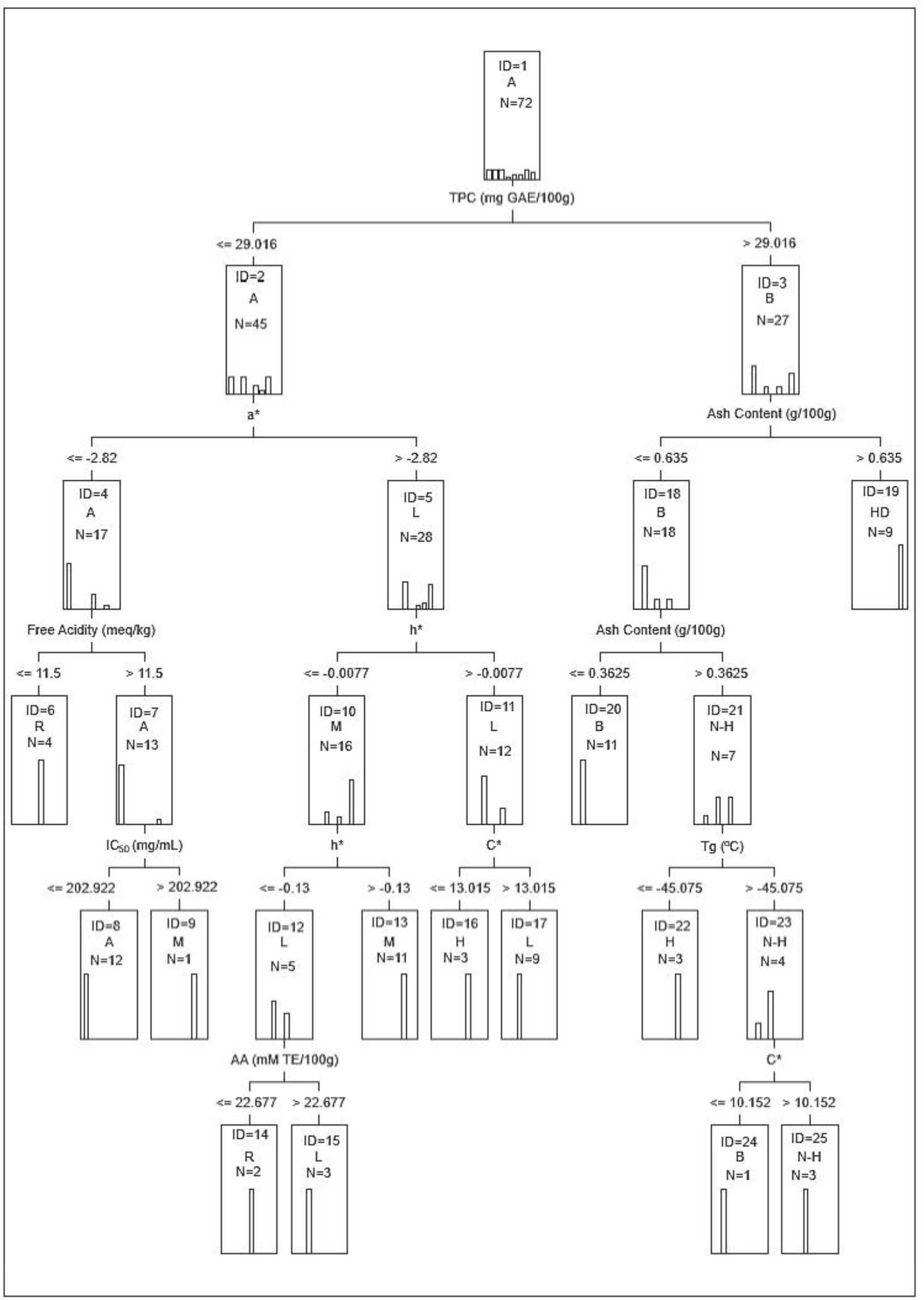

FIGURE 4. Classification and regression tree (C\&RT) for honey types.

$\mathrm{L}^{*}, \mathrm{a}^{*}, \mathrm{~b}^{*}, \mathrm{~h}^{*}$ and $\mathrm{C}^{*}$ - colour indices, TPC - total phenolic content, $\mathrm{IC}_{50}, \mathrm{AA}$ - antioxidant activity, $\mathrm{Tg}$ - glass transition temperature, A - acacia honey, $\mathrm{R}$ - rape honey, $\mathrm{L}$ - linden honey, $\mathrm{M}$ - multifloral honey, $\mathrm{N}-\mathrm{H}$ - nectar-honeydew honey, $\mathrm{B}$ - buckwheat honey, $\mathrm{H}$ - honeydew honey, $\mathrm{H}$ - heather honey. 
TABLE 4. Summary of Artificial Neural Network - Multilayer Perceptron (ANN-MLP) models.

\begin{tabular}{l|c|c|c|c|c|c|c}
\hline MLP model & $\begin{array}{c}\text { Training } \\
\text { performance }\end{array}$ & $\begin{array}{c}\text { Test } \\
\text { performance }\end{array}$ & $\begin{array}{c}\text { Validation } \\
\text { performance }\end{array}$ & $\begin{array}{c}\text { Training } \\
\text { algorithm }\end{array}$ & $\begin{array}{c}\text { Error } \\
\text { function }\end{array}$ & $\begin{array}{c}\text { Hidden } \\
\text { activation }\end{array}$ & $\begin{array}{c}\text { Output } \\
\text { activation }\end{array}$ \\
\hline $13-13-8$ & 100 & 100 & 100 & BFGS 67 & SOS & Tanh & Sinus \\
$13-10-8$ & 100 & 100 & 100 & BFGS 67 & SOS & Tanh & Tanh \\
$13-10-8$ & 100 & 100 & 100 & BFGS 68 & SOS & Tanh & Tanh \\
$13-13-8$ & 100 & 100 & 100 & BFGS 71 & SOS & Tanh & Tanh \\
$13-10-8$ & 100 & 100 & 100 & BFGS 52 & SOS & Tanh & Identity \\
$13-10-8$ & 100 & 100 & 100 & BFGS 13 & Entropy & Tanh & Softmax \\
$13-10-8$ & 100 & 100 & 100 & BFGS 17 & Entropy & Tanh & Softmax \\
\hline
\end{tabular}

SOS - sum of squares, BFGS - Broyden-Fletcher-Goldfarb-Shanno technique for training neural networks.

in the testing set correctly classified during the networks testing step; and validation performance as a percentage of the samples in the validation set (samples not used in the learning and testing steps) correctly classified by the models during the networks validation step. Performances of the obtained models are presented in Table 4. All the built networks were characterised by a perfect learning and testing performance $(100 \%)$. Only the validation performance for the fourth model was lower than $100 \%$.

\section{CONCLUSIONS}

In perspective of the outcomes achieved inside this investigation, it can be concluded that a discriminant approach based on the combination of physicochemical parameters, thermal analysis and antioxidant properties together with appropriate chemometric techniques is a promising and effective way for differentiating honeys conforming to their botanical origin. The colour parameters were important in discriminating honey samples using all multivariate technics. The rest of the analysed in this study physicochemical properties of honey were also important but their discriminating power depends on the statistical methods which were applied. In conclusion, this study demonstrated the high potential of the selected chemometric methods combined with the honeys selected properties in honey analysis for providing reliable results and models of simple application. The results presented in this paper jointly with the models could certainly be developed further to completely approve the adequacy of the method, using a greater number of samples from other honey types collected from other regions.

\section{RESEARCH FUNDING}

Research was supported by the Ministry of Science and Higher Education (Poland) as part of the statutory activities of the Department of Food Quality and Safety Management of the Poznań University of Life Sciences, Poznań.

\section{CONFLICT OF INTERESTS}

Authors declare no conflict of interests.

\section{REFERENCES}

1. Ahmed, J., Prabhu, S.T., Raghavan, G.S.V., Ngadi, M. (2007). Physico-chemical, rheological, calorimetric and dielectric behavior of selected Indian honey. Journal of Food Engineering, 79(4), 1207-1213.

2. Al-Mamary, M., Al-Meeri, A., Al-Habori, M. (2002). Antioxidant activities and total phenolics of different types of honey. Nutrition Research, 22(9), 1041-1047.

3. Al, M.L., Daniel, D., Moise, A., Bobis, O., Laslo, L., Bogdanov, S. (2009). Physico-chemical and bioactive properties of different floral origin honeys from Romania. Food Chemistry, 112(4), 863-867.

4. Alvarez-Suarez, J.M., González- Paramás, A.M., Santos-Buelga, C., Battino, M. (2010). Antioxidant characterization of native monofloral Cuban honeys. Journal of Agricultural and Food Chemistry, 58(17), 9817-9824.

5. Alves, A., Ramos, A., Gonçalves, M.M., Bernardo, M., Mendes, B. (2013). Antioxidant activity, quality parameters and mineral content of Portuguese monofloral honeys. Journal of Food Composition and Analysis, 30(2), 130-138.

6. Anjos, O., Iglesias, C., Peres, F., Martínez, J., García, Á., Taboada, J. (2015). Neural networks applied to discriminate botanical origin of honeys. Food Chemistry, 175, 128-136.

7. AOAC (1995). Official Methods of Analysis. Washington, DC: Association of Official Analytical Chemists.

8. AOAC (1996). Official Methods of Analysis (16th ed.). Washington, DC: Association of Official Analytical Chemists. Method: 962.19 vol. II.

9. Baltrušaitytė, V., Venskutonis, P.R., Čeksterytè, V. (2007). Radical scavenging activity of different floral origin honey and beebread phenolic extracts. Food Chemistry, 101 (2), 502-514.

10. Benedetti, S., Mannino, S., Sabatini, A.G., Marcazzan, G.L. (2004). Electronic nose and neural network use for the classification of honey. Apidologie, 35(4), 397-402.

11. Bentabol Manzanares, A., García, Z.H., Galdón, B.R., Rodríguez, E.R., Romero, C.D. (2011). Differentiation of blossom and honeydew honeys using multivariate analysis on the physicochemical parameters and sugar composition. Food Chemistry, 126(2), 664-672.

12. Beretta, G., Granata, P., Ferrero, M., Orioli, M., Maffei Facino, R. (2005). Standardization of antioxidant properties of honey 
by a combination of spectrophotometric/fluorimetric assays and chemometrics. Analytica Chimica Acta, 533(2), 185-191.

13. Berrueta, L.A., Alonso-Salces, R.M., Héberger, K. (2007). Supervised pattern recognition in food analysis. Journal of Chromatography A, 1158(1-2), 196-214.

14. Bertelli, D., Lolli, M., Papotti, G., Bortolotti, L., Serra, G., Plessi, M. (2010). Detection of honey adulteration by sugar syrups using one-dimensional and two-dimensional High-Resolution Nuclear Magnetic Resonance. Journal of Agricultural and Food Chemistry, 58(15), 8495-8501.

15. Bertoncelj, J., Doberšek, U., Jamnik, M., Golob, T. (2007). Evaluation of the phenolic content, antioxidant activity and colour of Slovenian honey. Food Chemistry, 105(2), 822-828.

16. Bogdanov, S., Ruoff, K., Persano Oddo, L. (2004). Physicochemical methods for the characterisation of unifloral honeys: a review. Apidologie, 35, Suppl. 1, 4-17.

17. Bogdanov, S., Jurendic, T., Sieber, R., Gallmann, P. (2008). Honey for nutrition and health: A Review. Journal of the American College of Nutrition, 27(6), 677-689.

18. Brudzynski, K., Miotto, D. (2011a). Honey melanoidins: Analysis of the compositions of the high molecular weight melanoidins exhibiting radical-scavenging activity. Food Chemistry, 127(3), 1023-1030.

19. Brudzynski, K., Miotto, D. (2011b). The recognition of high molecular weight melanoidins as the main components responsible for radical-scavenging capacity of unheated and heat-treated Canadian honeys. Food Chemistry, 125(2), 570-575.

20. Chudzinska, M., Baralkiewicz, D. (2010). Estimation of honey authenticity by multielements characteristics using inductively coupled plasma-mass spectrometry (ICP-MS) combined with chemometrics. Food and Chemical Toxicology, 48(1), 284-290.

21. Cordella, C., Antinelli, J.-F., Aurieres, C., Faucon, J.-P., Cabrol-Bass, D., Sbirrazzuoli, N. (2002). Use of differential scanning calorimetry (DSC) as a new technique for detection of adulteration in honeys. 1. Study of adulteration effect on honey thermal behavior. Journal of Agricultural and Food Chemistry, 50(1), 203-208.

22. Council Directive 2001/110/EC of 20 December 2001 relating to honey. Official Journal of the European Communities, L 10, 12.1.2002, 47

23. de la Fuente, E., Ruiz-Matute, A.I., Valencia-Barrera, R.M., Sanz, J., Martínez Castro, I. (2011). Carbohydrate composition of Spanish unifloral honeys. Food Chemistry, 129(4), 1483-1489.

24. Dżugan, M., Tomczyk, M., Sowa, P., Grabel-Lejko, D. (2018). Anioxidant activity as biomarker of honey variety. Molecules, 23(8), art. no. 2069.

25. Estevinho, L., Pereira, A.P., Moreira, L., Dias, L.G., Pereira, E. (2008). Antioxidant and antimicrobial effects of phenolic compounds extracts of Northeast Portugal honey. Food and Chemical Toxicology, 46(12), 3774-3779.

26. Gheldof, N., Wang, X.-H., Engeseth, N.J. (2002). Identification and quantification of antioxidant components of honeys from various floral sources. Journal of Agricultural and Food Chemistry, 50(21), 5870-5877.

27. Gonzalez-Miret, M.L., Terrab, A., Hernanz, D., Fernández-Recamales, M.Á., Heredia, F.J. (2005). Multivariate correlation between color and mineral composition of honeys and by their botanical origin. Journal of Agricultural and Food Chemistry, 53(7), 2574-2580.
28. Habib, H.M., Al Meqbali, F.T., Kamal, H., Souka, U.D., Ibrahim, W.H. (2014). Physicochemical and biochemical properties of honeys from arid regions. Food Chemistry, 153, 35-43.

29. Juszczak, L., Socha, R., Rożnowski, J., Fortuna, T., Nalepka, K. (2009). Physicochemical properties and quality parameters of herbhoneys. Food Chemistry, 113(2), 538-542.

30. Krpan, M., Marković, K., Šarić, G., Skoko, B., Hruškar, M., Vahčić, N. (2009). Antioxidant activities and total phenolics of acacia honey. Czech Journal of Food Science, 27, SI, S245$-\mathrm{S} 247$.

31. Lazaridou, A., Biliaderis, C.G., Bacandritsos, N., Sabatini, A.G. (2004). Composition, thermal and rheological behaviour of selected Greek honeys. Journal of Food Engineering, 64(1), 9-21.

32. Madejczyk, M., Baralkiewicz, D. (2008). Characterization of Polish rape and honeydew honey according to their mineral contents using ICP-MS and F-AAS/AES. Analytica Chimica Acta, 617(1-2), 11-17.

33. Meda, A., Lamien, C.E., Romito, M., Millogo, J., Nacoulma, O.G. (2005). Determination of the total phenolic, flavonoid and proline contents in Burkina Fasan honey, as well as their radical scavenging activity. Food Chemistry, 91(3), 571-577.

34. Mellen, M., Fikselová, M., Mendelová, A., Haščik, P. (2015). Antioxidant effect of natural honeys affected by their source and origin. Polish Journal of Food and Nutrition Sciences, 65(2), $81-85$.

35. Młodzińska, E. (2009). Survey of plant pigments: molecular and environmental determinants of plant colors. Acta Biologica Cracoviensia, Series Botanica, 51(1), 7-16.

36. Muzolf-Panek, M., Waskiewicz, A., Kowalski, R., Konieczny, P. (2016). The effect of blueberries on the oxidative stability of pork meatloaf during chilled storage. Journal of Food Processing and Preservation, 40, 899-909.

37. Nayik, G.A., Nanda, V. (2016). A chemometric approach to evaluate the phenolic compounds, antioxidant activity and mineral content of different unifloral honey types from Kashmir, India. LWT - Food Science and Technology, 74, 504-513.

38. Nayik, G.A., Suhag, Y., Majid, I., Nanda, V. (2016). Discrimination of high altitude Indian honey by chemometric approach according to their antioxidant properties and macro minerals. Journal of the Saudi Society of Agricultural Sciences, 17(2), 200-2007.

39. Pasini, F., Gardini, S., Marcazzan, G.L., Caboni, M.F. (2013). Buckwheat honeys: screening of composition and properties. Food Chemistry, 141(3), 2802-2811.

40. Polish Standard PN-88/A-77626 (1998). Honeybee honey. Dziennik Norm i Miar nr 8, Wydawnictwo Normalizacyjne Alfa (in Polish).

41. Popek, S., Halagarda, M., Kursa, K. (2017). A new model to identify botanical origin of Polish honeys based on the physicochemical parameters and chemometric analysis. $L W T-$ Food Science and Technology, 77, 482-487.

42. Sánchez-Moreno, C., Larrauri, J.A., Saura-Calixto, F. (1998). A procedure to measure the antiradical efficiency of polyphenols. Journal of the Science of Food and Agriculture, 270(2), 270-276.

43. Sanz, M.L., Gonzalez, M., de Lorenzo, C., Sanz, J., Martínez-Castro, I. (2005). A contribution to the differentiation between nectar honey and honeydew honey. Food Chemistry, 91 (2), 313-317 .

44. Siddiqui, A.J., Musharraf, S.G., Choudhary, M.I., Rahman, A. (2017). Application of analytical methods in authentication and adulteration of honey. Food Chemistry, 217, 687-698. 
45. Singleton, V.L., Rossi, J.A. (1965). Colorimetry of total phenolics with phosphomolybdic-phosphotungstic acid reagents. American Journal of Enology and Viticulture, 16(3), 144 LP-158.

46. Tomaszewska-Gras, J., Bakier, S., Goderska, K., Mansfeld, K. (2015). Differential scanning calorimetry for determining the thermodynamic properties of selected honeys. Journal of Apicultural Science, 59(1), 109-118.

47. Tonon, R.V., Baroni, A.F., Brabet, C., Gibert, O., Pallet, D., Hubinger, M.D. (2009). Water sorption and glass transition tempera- ture of spray dried açai (Euterpe oleracea Mart.) juice. Journal of Food Engineering, 94(3-4), 215-221.

48. Tuberoso, C.I. G., Jerković, I., Sarais, G., Congiu, F., Marijanović, Z., Kuś, P.M. (2014). Color evaluation of seventeen European unifloral honey types by means of spectrophotometrically determined CIE L* $\mathrm{C}_{\mathrm{ab}} \mathrm{H}_{\mathrm{ab}}{ }^{\circ}$ chromaticity coordinates. Food Chemistry, 145, 284-291.

Submitted: 20 September 2018. Revised: 7 March and 10 April 2019. Accepted: 15 April 2019. Published on-line: 31 May 2019. 